Статья с открытым доступом под лицензией CC BY-NC-ND (https://creativecommons.org/licenses/by-nc-nd/3.0/) Материалы Международной практической интернет-конференции «Актуальные проблемы науки»

Выпуск II, ноябрь 2019

ISBN 978-601-323-144-0

https://doi.org/10.31643/2019.006

\author{
Яковишена Людмила \\ Винницкий педагогический университет \\ им. М. Коцюбинского, Украина \\ E-mail: ludmilayakovishena@gmail.com \\ ORCID ID 0000-0001-9197-8538
}

\title{
Методологические подходы формирования профессиональной компетентности будущих младших медицинских специалистов
}

\begin{abstract}
Абстракт: В статье проанализированы методологические подходы сформированности профессиональной компетентности будущих младших медицинских специалистов в процессе изучения естественно-научных дисциплин. Очерчено, что реализация аксиологического подхода позволяет определить содержательные особенности процесса формирования профессиональной компетентности будущих младших медицинских специалистов; компетентностного - позволяет по новому подойти к решению проблемы качества подготовки будущего специалиста, способного эффективно действовать в различных профессиональных ситуациях и стать конкурентоспособным на рынке труда; деятельностного - обеспечивает рассмотрение отдельных компонентов педагогического процесса не изолированно, а во взаимосвязи и взаимодействии; междисциплинарного - предусматривает обеспечение целостности знаний основываясь на взаимопроникновении, сближении учебных дисциплин на основе похожих понятий, явлений и процессов как для естественнонаучного, так и профессионально-практического цикла; синергетический - позволяет создать образовательную среду в медицинском колледже, которое основывается на принципах студентоцентризму, направленное на развитие личности и способно обеспечить эффективный процесс формирования профессиональной компетентности студента; личностно-ориентированный - предоставляет возможность создать определенное образовательное среду, обеспечивающую: знание педагога, индивидуальный подход к студенту, раскрытие способностей и возможностей каждого студента, связь психологических особенностей личности с учебным процессом, формирование самостоятельности самоактивности личности. Определино принцип профессиональной направленности в процессе формирования профессиональной компетентности будущих младших медицинских специалистов как таковой, который сконцентрирован на усвоении содержания фундаментальных основ естественнонаучных дисциплин на уровне потребностей и требований к профессии медицинского работника.
\end{abstract}

Ключевые слова: методологический подход, профессиональная компетентность, будущий младший медицинский специалист.

\section{Введение}

В современных условиях государства основное направление модернизации профессионального образования отражается в «Концепции развития высшего медицинского образования в Украине» и «Национальной стратегии построения новой системы здравоохранения в Украине на 2015-2020 гг.» и связан с реализацией компетентностного подхода. Это обусловлено необходимостью повышения качества образования в Украине и изменением парадигмы образовательного процесса, направленной на усиление практической составляющей результатов обучения.

Ключевые вопросы реформирования медицинского образования связаны с понятием уровня компетентности и профессионализма, и как следствие - задачей повышение престижа, авторитета и социального статуса профессии младшего медицинского специалиста. Профессиональная компетентность специалиста формируется, главным образом, в процессе его профессиональной 
деятельности, однако, в ряде педагогических исследований доказана мысль о том, что формирование компонентов профессиональной компетентности возможно в процессе обучения, причем средствами не только профессиональных но и естественно-научных дисциплин. При этом физика, астрономия и математика как фундаментальные естественные науки играют роль системообразующего фактора формирования компонентов профессиональной компетентности за счет реализации межпредметных связей, как средства интеграции содержания фундаментальной и профессиональной подготовки.

Проблему подготовки будущих специалистов исследовали И. Зязюн, Г. Васянович, Г. Гуревич, А. Коломиец, В. Кремень, М. Ковтонюк, С. Слепкань, Н. Ничкало, С. Сысоева и др; подготовки студентов в медицинском колледже Я. Цехмистер, А. Кравченко, В. Копетчук, И. Сирак, И. Сурсаева, И. Гук, А. Кравченко, А. Кривонос, К. Соцький, И. Тимощук и др.

\section{Исследовательские подходы}

Для достижения результата - положительная динамика сформированности профессиональной компетентности будущих младших медицинских специалистов использовались такие методологические подходы: аксиологический, системный, личностно-ориентированный, синергетический, компетентностный, деятельностный, междисциплинарный, учебноисследовательский (Яковишена Л.О., 2019). Рассмотрим некоторые из них.

Аксиологический подход рассматривает формирование профессиональной компетентности как целостное явление, определенную систему ценностей, проявляющихся в отношении положительного личностного значение профессиональной компетентности для студентов медицинского колледжа. Реализация данного подхода позволяет определить содержательные особенности процесса формирования профессиональной компетентности будущих младших медицинских специалистов, обоснованно выбрать педагогические методы, средства и формы для эффективной организации учебного процесса.

Компетентностный подход позволяет представить профессиональную компетентность как набор компетенций (специальная, общая, деонтологическая, акмеологическая, интернациональная, самообразовательная, валеологическая, техническая, социально-коммуникативная, информационноаналитическая), которые формируются в процессе обучения и проявляются в профессиональной деятельности. Применение компетентностного подхода в процессе преподавания научноестественных дисциплин в медицинском колледже решает следующие задачи:

$>$ дифференциация учебного материала;

$>$ разработка и отбор инновационных методов, приемов и средств обучения;

$>$ применение ИК технологий;

$>$ разработка объективной системы мониторинга знаний.

Реализация данного подхода в подготовке будущих специалистов позволяет по новому подойти к решению проблемы качества подготовки будущего специалиста, способного эффективно действовать в различных профессиональных ситуациях и стать конкурентоспособным на рынке труда.

Деятельностный подход определяет профессиональную компетентность как особый вид деятельности и предполагает направленность всех педагогических методов и форм на организацию интенсивного учебно-предметного процесса обучения. Данный подход дал основание исследовать формирование профессиональной компетентности будущего младшего медицинского специалиста как превращение его личностных качеств, осуществлялось в специально организованной учебной среде, в связи с чем профессиональная компетентность студента проявляется как целенаправленная и мотивированная профессиональная деятельность. Применяя данный подход в нашем исследовании мы учитывали необходимость совокупности фундаментальных общеобразовательных и профессиональных знаний и наличия конкретных умений и навыков, необходимых для выполнения определенного комплекса действий для осуществления профессиональной деятельности.

Обеспечение процесса формирования профессиональной компетентности будущих младших медицинских специалистов осуществлялась на реализации системного подхода, который распределяет проблему исследуемого явления на отдельные аспекты в соответствии с поставленными задачами, для решения которых существуют методы их реализации (Кустовская. А. В., 2015). Реализация данного подхода в подготовке будущих младших медицинских специалистов 
обеспечивает рассмотрение отдельных компонентов педагогического процесса (цель, содержание образования, методы, формы и средства обучения, деятельность преподавателя и студентов) не изолированно, а во взаимосвязи и взаимодействии. Профессиональная компетентность будущих младших медицинских специалистов в колледже формируется на протяжении всего процесса обучения начиная с первого курса, где происходит общеобразовательная подготовка значительную часть которой занимают естественные дисциплины, такие как: «Физика и астрономия», «Биология и экология», «Химия, «География» и продолжается на следующих курсах интегрируя в цикл естественно-научной подготовки: «Основы биологической физики и медицинская аппаратура», «Медицинская биология», «Микробиология», «Основы экологии и профилактической медицины», «Медицинская химия». По мнению А. Краевской, системный подход опредиляет общие закономерности в различных областях, таким образом развивает связи между различными дисциплинами (Краевская А.Д., 2015). Соглашпемось с мнением ученого и считаем уместным применение данного подхода при формировании профессиональной компетентности будущих младших медицинских специалистов в процессе изучения естественно-научных дисциплин, который является основой для реализации междисциплинарного подхода.

Междисциплинарный подход не ограничивает знания, а создает условия для реализации связей между различными науками, способными обеспечить при изучении объекта исследования необходимые и достаточные знания, сосредотачиваясь при этом на собственном предмете в целостном явлении. Данный подход решает существующие в предметной системе обучения противоречия между разрозненным усвоением знаний и необходимостью их синтеза, целостного и комплексного применения на практике, в деятельности и жизни человека (Сысоева С. А. (2015)). Реализация данного подхода в подготовке будущих младших медицинских специалистов предусматривает обеспечение целостности знаний основываясь на взаимопроникновении, сближении учебных дисциплин на основе похожих понятий, явлений и процессов как для естественнонаучного, так и профессионально-практического цикла.

Применение междисциплинарного подхода в процессе профессиональной подготовки будущих младших медицинских специалистов рассматривается нами как часть общей проблемы формирования их профессиональной компетентности (Пайкуш М.А., 2019).

Синертетичний подход рассматривает образовательную деятельность личности как самоорганизационный процесс, соответствующий принципам открытости, нелинейности в развитии, неустойчивости, непредсказуемости, вероятностным переходам от одного состояния знаний к другому (Кремень В. Г., Ильин В. В., 2012, с.13). Концепция данного подхода в образовании построена в контексте человекоцентризма, где центром учебного процесса является личность, которая способна к самоопределению, самовыражению и самореализации в образовательной среде. Современное стремительное развитие электронных информационных ресурсов, свободный доступ к любой информации привел к пониманию, что студент часто не в состоянии выбрать нужный материал, выделить главное, качественно обработать и усвоить его. В таких условиях преподаватель учреждения высшего образования сталкивается с необходимостью создания собственного образовательного пространства, который сосредоточен на потребностях учебной деятельности студента. Реализация данного подхода в подготовке будущих младших медицинских специалистов в процессе изучения естественно-научных дисциплин дает возможность создать образовательную среду в медицинском колледже, которое основывается на принципах студентоцентризму, направленных на развитие личности и способно обеспечить эффективный процесс формирования профессиональной компетентности студента. Условием формирования профессиональной компетентности как целостной синергетической структуры для студента является не только материально-техническая база учебного заведения, дает возможность использования современных информационно-коммуникативных технологий, но и наличие собственных мотивационных ресурсов.

Личностно-ориентированный подход - это один из важных принципов психологопедагогической науки, требующий ориентацию учебного процесса на конкретную личность и предусматривает создание такого образовательно-воспитательной среды, что обеспечивает ее индивидуальность в развитии и саморазвития. И. Зимня подчеркивает, что суть личностноориентированного подхода, заключается в организации субъект-субъектного взаимодействия педагога и обучаемого (студента), формировании его активности в обучении, готовности к решению 
нестандартных и проблемных задач; обеспечении внешней и внутренней мотивации студента; обеспечении условий для самооценки, саморегуляции, самоактуализации личности студента; изменения роли и функций педагога с контроллера знаний на роль помощника, функция которого обеспечить качественные условия для эффективной деятельности студента (Якиманская И. С.,1995). По мнению И. Якиманской, в основе личностно ориентированного подхода «лежит признание индивидуальности, самоценности каждого человека, его развития не как коллективного объекта, но, прежде всего, как индивида, наделенного своим неповторимым субъективным опытом» (Дубасенюк А. А., 2012).

Личностно ориентированное образование - целенаправленный, планомерный, непрерывный, специально организованный педагогический процесс, направленный на развитие и саморазвитие ученика, становление его как личности с учетом индивидуальных особенностей, интересов, способностей (Зимняя И. А., 1997, с.16).

Подготовка студентов на основе личностно-ориентированного обучения в медицинском колледже - это тесная, непрерывный процесс субъект-субъектного взаимодействия преподавателя и студента, происходит на основе всестороннего учета индивидуальных потребностей и возможностей студента и направлен на усвоение соответствующих предметных знаний, умений и навыков, как средства индивидуальности в развитии, саморазвития личностных качеств, формирование жизненных и профессиональных компетенций. Реализация данного подхода в подготовке будущих младших медицинских специалистов в процессе изучения естественнонаучных дисциплин дает возможность создать определенное образовательное среду, обеспечивающую: знание педагога индивидуальных особенностей своих студентов (темперамент, особенности доминирующей модальности, развития); индивидуальный подход к студенту как к личности с пониманием его как целостной системы; раскрытие способностей и возможностей каждого студента и всестороннее и гармоничное развитие его индивидуальности; связь психологических особенностей личности с учебным процессом; формирование самостоятельности самоактивности личности. Дидактико-методическое обеспечение личностно-ориентированного обучения предполагает усиление в содержании профессиональной подготовки студентов человековедческих, личностно значимого, эмоциогенного материала, создание методик на основе диалогического взаимодействия, познавательного интереса, ситуации выбора, рефлексии, стимулирования, сохранения эмоциональной комфортности и реализации «педагогики успеха» ( Энциклопедия образования, 2008, с.627).

Именно личностно-ориентированный подход определяет место студента в учебновоспитательном процессе, подтверждает признание его активным субъектом деятельности, таким образом способствует становлению субъект-субъектных отношений.

\section{Вывод}

Таким образом, определяем принцип профессиональной направленности в процессе формирования профессиональной компетентности будущих младших медицинских специалистов как таковой, который сконцентрирован на усвоении содержания фундаментальных основ естественнонаучных дисциплин на уровне потребностей и требований к профессии медицинского работника а также обеспечивает овладение теоретических естественнонаучных знаний для дальнейшего изучения клинических дисциплин.

Профессиональную направленность обучения естественно-научных дисциплин в медицинском колледже рассматриваем как сложный комплексный многофункциональный процесс, направленный на осознание мотивов, потребностей будущей деятельности, на гармоничное сочетание теоретической и практической составляющих содержания образования - введение в содержание предметов профессионально значимого учебного материала, использование интерактивных методов и форм работы.

Благодарность. Работа выполнена при поддержке Государственного педагогического университета им. М. Коцюбинского г. Винница, Республика Украина / Министерства образования и науки Республики Украина. Автор выражает благодарность Ковтонюк М.М., Гуревич Р.С., Коломиец А.Н. 


\author{
Yakovyshena Lyudmila \\ Vinnytsia M. Kotsiubynskyi State Pedagogical University, Ukraine \\ E-mail: ludmilayakovishena@gmail.com \\ ORCID ID 0000-0001-9197-8538
}

\title{
Methodological approaches of forming of professional competence of future junior medical specialists
}

\begin{abstract}
In the article methodological approaches (aksiologicheskiy, system, personality-oriented, synergetics, kompetentnostnyy, deyatel'nostnyy) of formed of professional competence of future junior medical specialists are analysed in the process of study of estestvenno-nauchnykh disciplines. It is outlined, that realization of aksiologicheskogo approach allows to define the rich in content features of process of forming of professional competence of future junior medical specialists; kompetentnostnogo - allows on new to walk up to the decision of problem of quality of preparation of future specialist, capable effectively to operate in different professional situations and become competitive at the market of labour; deyatel'nostnogo -obespechivaet consideration of separate components of pedagogical process not isolated, but in intercommunication and co-operation; mezhdisciplinarnogo - foresees providing of integrity of knowledges based on an interpenetration, rapprochement of educational disciplines on the basis of alike concepts, phenomena and processes both for estestvennonauchnogo and professional-practical cycle; synergetics - allows to create an educational environment in a medical college, which is based on principles of studentocentrizmu, directed on development of personality and able to provide the effective process of forming of professional competence of student; personality-oriented - gives possibility to create certain educational environment, providing: knowledge of teacher, individual going near a student, opening of capabilities and possibilities of every student, connection of psychological features of personality with an educational process, forming of independence of selfactivity of personality. Opredelino principle of professional orientation in the process of forming of professional competence of future junior medical specialists as such, which is concentrated on mastering of maintenance of fundamental bases of estestvennonauchnykh disciplines at the level of necessities and requirements to the profession of medical worker.
\end{abstract}

Keywords: methodological approach, professional competence, future junior medical specialist.

Ссылка на данную статью: Яковишена Л.О. (2019). Методологические подходы формирования профессиональной компетентности будущих младших медицинских специалистов. Материалы Международной практической интернетконференции «Актуальные проблемы науки» / Materials of International Practical Internet Conference "Challenges of Science". ISBN 978-601-323-144-0. Выпуск II, 2019. Стр.: 37 42. https://doi.org/10.31643/2019.006

\section{Список литературных источников}

[1]. Дубасенюк А. А. (2012). Профессиональная педагогическое образование: личностно ориентированный поход. Житомир: ЖДУ им. И. Франко, 436 с.

[2]. Зимняя И. А. (1997). Педагогическая психология: учеб. пособие для вузов. Ростов на Дону: Феникс, 480 с

[3]. Энциклопедия образования. (2008). Акад. пед. наук Украины; глав. ред. В. Г. Кремень. Москва.

[4]. Кустовская А. В. (2015). Методология системного подхода и научных исследований: курс лекцій. Тернополь: Экономическая мысль, $124 \mathrm{c}$.

[5]. Краевская А. Д. (2015). Формирование коммуникативной компетентности будущих менеджеров-аграриев в процессе профессиональной подготовки: дис. ... канд. пед. наук: 13.00.04. Тернополь, 278 с.

[6]. Кремень В. Г., Ильин В. В. (2012). Синергетика в образовании: контекст человекоцентризма: монография. Киев: Педагогическая мисль, 368 с.

[7]. Макаренко А. В. (2017). Формирование исследовательской компетентности будущих врачей в процессе изучения естественных дисциплин: дис. ... канд. пед. наук: 13.00.04. Полтава, 262 с.

[8]. Пайкуш М. А. (2019). Теоретические и методические основы интеграции естественнонаучной и профессионально-практической подготовки будущих врачей: дис. ... д-ра. пед. наук: 13.00.04. Винница, 602 с.

[9]. Сысоева С. А. (2015). Дискуссионные аспекты научного тезауруса нового закона Украины «О высшем образовании». Непрерывное профессиональное образование: теория и практика, № 1-2 (42-43).

[10]. Якиманская И. С. (1995). Разработка технологии личностно-ориентированного обучения. Вопросы психологии. № 2. С. 9.

[11]. Яковишена Л. А. (2019). Внедрение принципа научности в обучении естественно-научных дисциплин будущих медицинских специалистов. Стратегии инновационного развития естественных дисциплин: опыт, проблемы и перспективы: материалы II всеукр. научно-практической. интернет-конф. Кропивницкий, С.250-252. 